Article

\title{
Wedge-Splitting Test on Carbon-Containing Refractories at High Temperatures
}

\author{
Martin Stückelschweiger ${ }^{1, *}$, Dietmar Gruber ${ }^{2}\left(\mathbb{D}\right.$, Shengli Jin ${ }^{2}\left(\mathbb{D}\right.$ and Harald Harmuth ${ }^{2}$ \\ 1 K1-MET GmbH, Linz 4020, Austria \\ 2 Chair of Ceramics, Montanuniversitaet Leoben 8700, Austria \\ * Correspondence: martin-josef.stueckelschweiger@alumni.unileoben.ac.at; Tel.: +43-3842-402-3207
}

Received: 4 July 2019; Accepted: 5 August 2019; Published: 8 August 2019

check for updates

\begin{abstract}
The mode I fracture behavior of ordinary refractory materials is usually tested with the wedge-splitting test. At elevated temperatures, the optical displacement measurement is difficult because of the convection in the furnace and possible reactions of refractory components with the ambient atmosphere. The present paper introduces a newly developed testing device, which is able to perform such experiments up to $1500^{\circ} \mathrm{C}$. For the testing of carbon-containing refractories a gas purging, for example, with argon, is possible. Laser speckle extensometers are applied for the displacement measurement. A carbon-containing magnesia refractory $(\mathrm{MgO}-\mathrm{C})$ was selected for a case study. Based on the results obtained from tests, fracture mechanical parameters such as the specific fracture energy and the nominal notch tensile strength were calculated. An inverse simulation procedure applying the finite element method yields tensile strength, the total specific fracture energy, and the strain-softening behavior. Additionally, the creep behavior was also considered for the evaluation.
\end{abstract}

Keywords: high-temperature wedge splitting test; fracture parameters; reducing condition; carbon-containing refractories; strain-softening; fracture energy

\section{Introduction}

The wedge-splitting test is performed on notched prismatic specimens that enable stable crack formation for relatively large specimens [1,2]. The reasons are the action of the wedge and the relatively high fracture surface to sample volume ratio. The specimen length is $100 \mathrm{~mm}$, the height is also $100 \mathrm{~mm}$, and the thickness $75 \mathrm{~mm}$. A three-dimensional schematic representation of the sample including the load transmission parts is shown in Figure 1. The wedge-splitting test (WST) at room temperature is performed with a loading rate of $0.5 \mathrm{~mm} / \mathrm{min}$. During the test, a video extensometer detects the horizontal displacement at the measuring points. The displacement is measured at the height where the rollers contact the load transmission elements. 


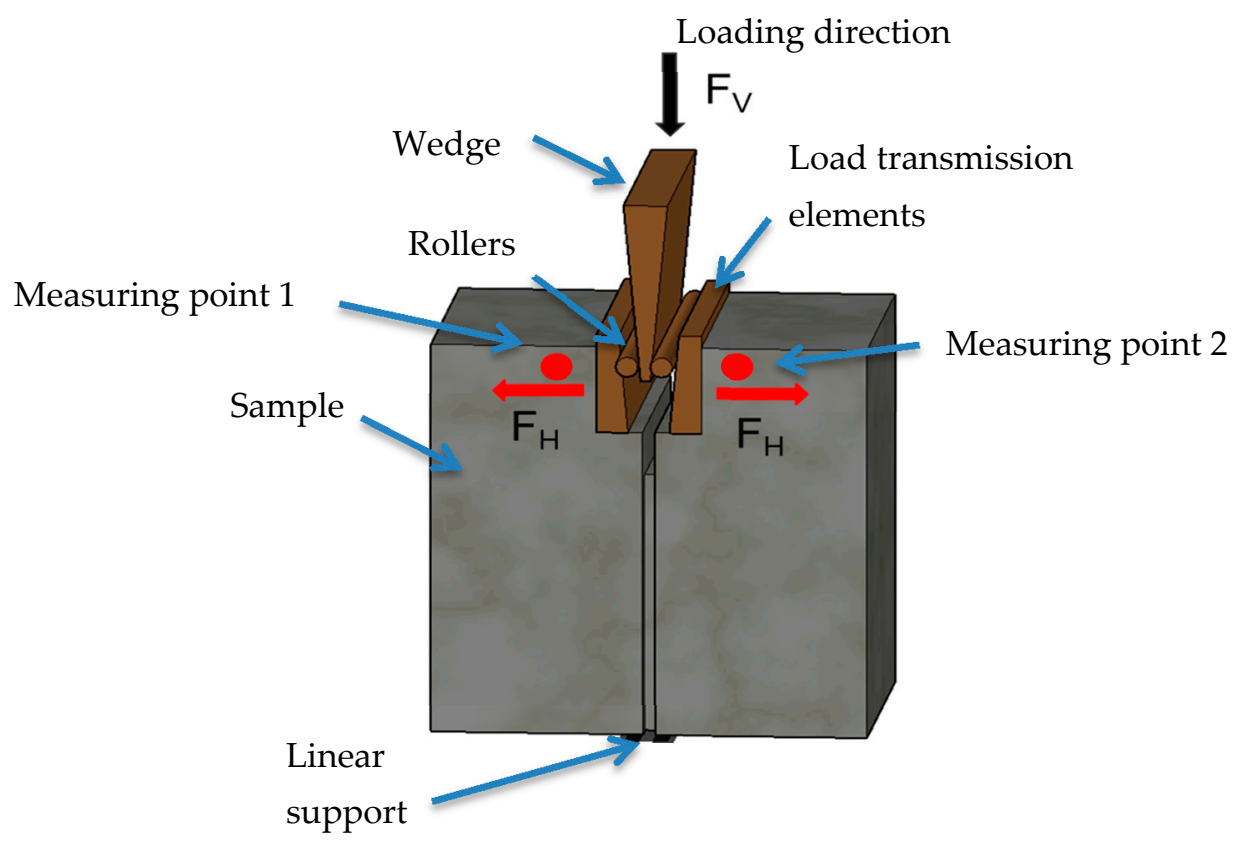

Figure 1. Schematic representation of the wedge-splitting test.

The sample rests on a linear support $\left(3 \times 3 \times 90 \mathrm{~mm}^{3}\right)$ to allow for the free vertical displacement of the sample except for the support. The linear support, as well as the wedge and the rollers, are made of corundum to withstand the testing temperatures.

From the results, the specific fracture energy $G_{f}{ }^{\prime}$ and the nominal notch tensile strength $\sigma_{N T}$, can be calculated directly from the load-displacement curve (Equations (2) and (3)). The horizontal force $F_{H}$, which is needed for Equations (2) and (3), is calculated from the geometry of the wedge and the measured vertical force $F_{V}$ (Equation (1)):

$$
F_{H}=\frac{F_{V}}{2 \tan \frac{\alpha}{2}}
$$

In this equation, $\alpha$ is the wedge angle $\left(10^{\circ}\right)$.

$$
G_{f^{\prime}}=\frac{1}{A} \int_{0}^{\delta} F_{H} d \delta_{H}
$$

The specific fracture energy $G_{f}^{\prime}$ is the area below the load-displacement curve divided by the ligament area $\mathrm{A}$. The measured horizontal displacement is defined with $\delta_{H}$, and the horizontal displacement at $15 \%$ of the maximum load is $\delta$.

Here $G_{f}^{\prime}$ (Equation (2)) is the specific fracture energy directly evaluated from the load-displacement curve. This parameter includes only the major part of the specific fracture energy because a premature termination of the test is necessary to avoid the contact of the wedge with the ligament. This means that the WST is stopped before the force reaches zero.

The nominal notch tensile strength $\sigma_{N T}$ is calculated according to Equation (3):

$$
\sigma_{N T}=\frac{F_{H, \max }}{b h}\left(1+\frac{6 y}{h}\right)
$$

Here, $F_{H, \max }$ is the maximum horizontal load, $b$ and $h$ are the width and the height of the ligament, and $y$ is the vertical distance from the loading position to the center of the ligament.

The simplest possibility for the displacement measurement is to make use of the crosshead travel. Unfortunately, this is not accurate because deformations of the testing machine influence the results as 
well as the adjustment of the load transmission parts during load application. Out of these reasons, it is advantageous to measure the displacement directly on the sample.

At elevated temperatures, one possibility is to measure the displacement with an optical dilatometer. Here a halogen lamp illuminates the sample on one side and on the other side the shadow cast by the sample against the light source is recorded by a high-resolution complementary metal-oxide-semiconductor (CMOS) camera [3]. With this method, the displacement is measured on one side of the sample only. Although the performance of the wedge splitting test at room temperature with optical displacement measurement is state of the art [4], at elevated temperatures, the optical measurement is far more difficult due to the radiation and convection in the furnace chamber.

High-temperature testing above $600^{\circ} \mathrm{C}$ of carbon-containing refractories shall be carried out in non-oxidizing atmospheres. Otherwise, the oxidation of carbon $2 \mathrm{C}_{(g)}+O 2_{(g)}=2 \mathrm{CO}_{(g)}$ takes place [5], and the microstructure and the properties will be changed significantly [6].

To counteract these problems, a new device was developed to perform the WST on carbon-containing materials up to $1500{ }^{\circ} \mathrm{C}$ in an argon atmosphere and to measure the displacement on the front and rear side of the sample. The horizontal displacements are measured with two laser speckle extensometers (LSE). In the present paper, the features of the new device and the fracture behavior of a resin-bonded magnesia carbon material at elevated temperatures are discussed.

\section{Material and Sample Preparation}

The tested resin bonded magnesia carbon brick is composed of fused magnesia, large crystal magnesia clinker, and graphite. A typical application is the refractory lining of a steel ladle in the secondary steel metallurgy. The residual carbon content after cooking under reducing conditions was $10 \%$. The composition showed a $\mathrm{CaO} / \mathrm{SiO}_{2}(\mathrm{C} / \mathrm{S})$ ratio of 3.8. Bricks were heat-treated at 1000 ${ }^{\circ} \mathrm{C}$ for $5 \mathrm{~h}$ in a coke bed prior to testing; this enhanced the carbon bond and reduced the emission of volatiles during testing. These emissions caused problems for the displacement measurement by laser speckle extensometers.

\section{Device}

The wedge splitting test device (universal testing device with displacement measurement) was developed in close cooperation with the company ZwickRoell Testing Systems GmbH (Furstenfeld, Austria). An existing universal testing device with a rigid frame and two rotating spindles were equipped with several components in order to perform the wedge-splitting test at high temperatures. A schematic drawing of the device is illustrated in Figure 2. The load cell is integrated in the lower piston and the maximum load capacity is $300 \mathrm{kN}$ at room temperature. The vertical load rate is set to $0.5 \mathrm{~mm} / \mathrm{min}$ for the wedge-splitting test.

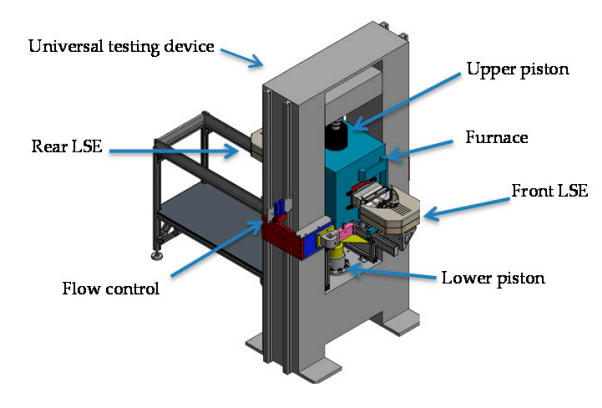

Figure 2. High-temperature testing device (courtesy of Messphysik).

In this device, a gas-tight furnace was installed (Figure 2, Figure 3). The furnace has two windows (front and rear) in order to measure the displacement during the test. The maximum testing temperature is $1500^{\circ} \mathrm{C}$. In order to protect the carbon in the samples from oxidation, the furnace chamber can be purged with an inert gas. The purging rate depends on the material and on the testing temperature 
and can be adjusted between 8 and $70 \mathrm{~L} / \mathrm{h}$. The adjustment of the purging rate was done with a valve at the digital flowmeter.

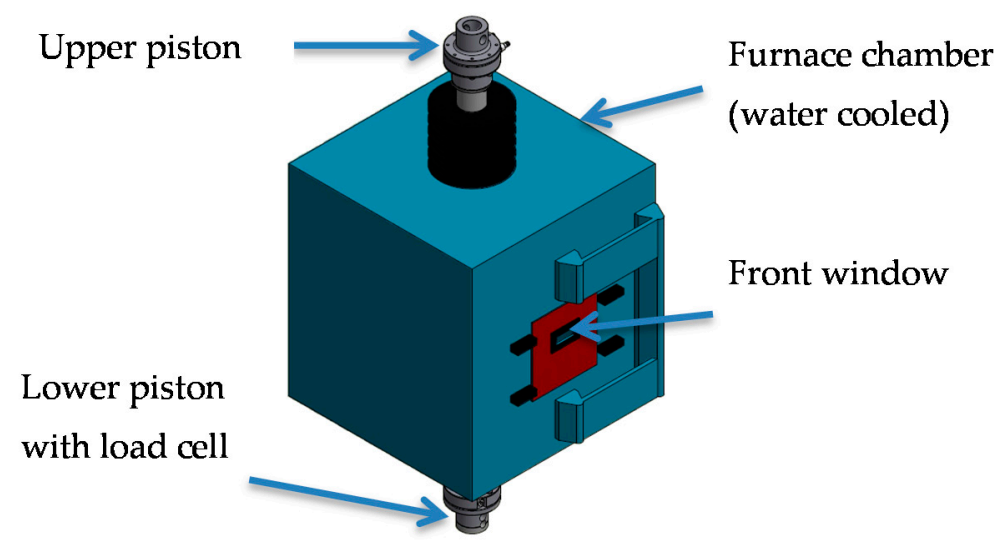

Figure 3. Gas-tight furnace (courtesy of Messphysik).

For the displacement measurement during the wedge-splitting test, the device was equipped with two laser-speckle extensometers. One is situated in the front and the other one in the rear of the furnace. The sample was illuminated with green laser light (wavelength: $532 \mathrm{~nm}$ ), creating a speckled pattern on the sample surface. The movement of the speckled pattern was recorded with two full-screen digital cameras. In each evaluation area, a displacement measurement of the speckled pattern was performed. The increase in the distance between the measurement points is calculated. It is called horizontal displacement in this paper [7].

The setup of the furnace including the laser-speckle extensometers is shown in Figure 4 (all units in $\mathrm{mm}$ ).

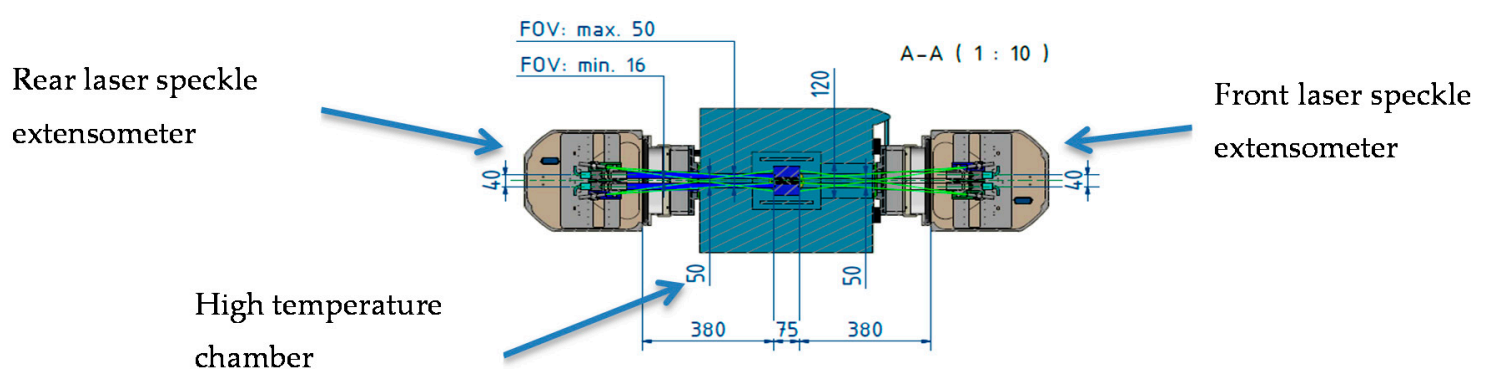

Figure 4. Furnace with two laser-speckle extensometers (courtesy of Messphysik).

Each extensometer has two lasers and two cameras. The green lines in Figure 4 show the course of the laser beam. The distance of the measuring points was set to $40 \mathrm{~mm}$. This initial measurement length can be adjusted according to the sample geometry. The distance between the position of the camera and the sample surface is $380 \mathrm{~mm}$.

The advantage of a laser-speckle-extensometer compared to a mechanical extensometer is that the sample and the extensometer fingers are not in contact. Contacting extensometer fingers could be damaged during the cracking of the sample, furthermore, a possible deformation of the extensometers could influence the results. An advantage compared to a standard laser extensometer is that an application of measuring marks to increase the contrast is not necessary because of the characteristic speckled pattern. The resolution of the strain measurement is $0.11 \mu \mathrm{m}$ according to the specifications from ZwickRoell. The scattering of the measurement signal during a high-temperature test was below $3 \mu \mathrm{m}$. This value was determined together with the company ZwickRoell in the course of preliminary investigations. The horizontal displacement was measured in the front and rear side, the average value was used for the evaluation. Figure 5 shows the configuration after a test. 


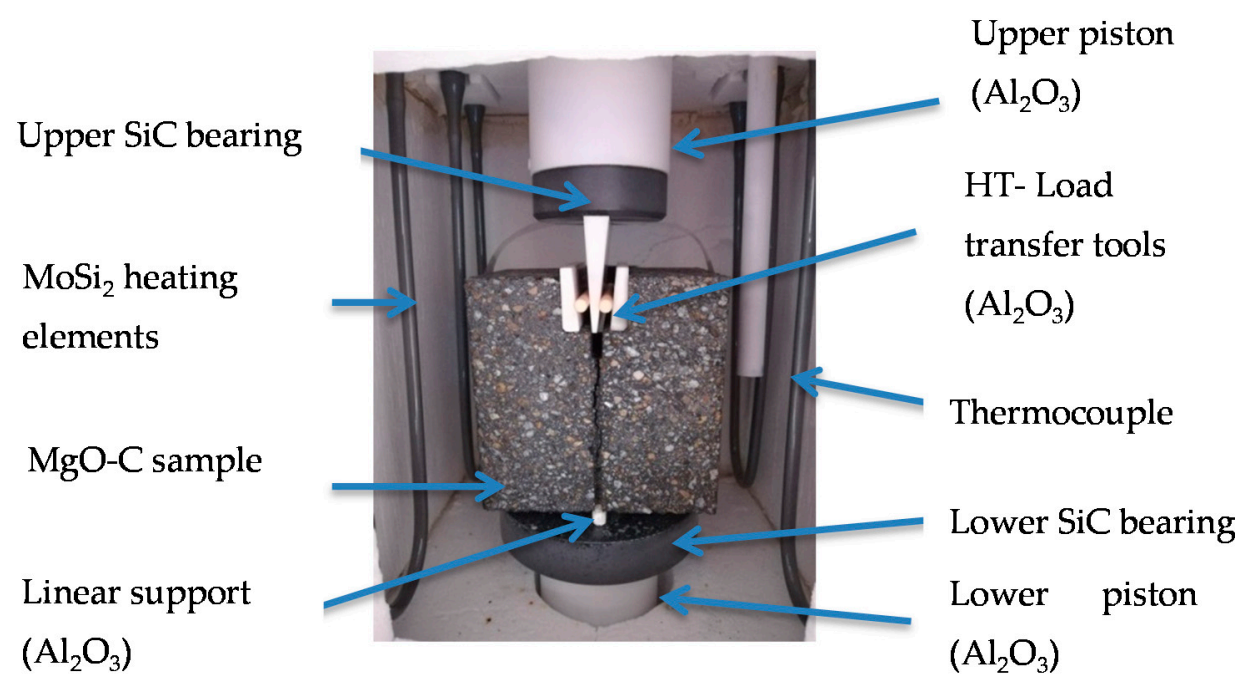

Figure 5. Wedge splitting test setup and sample after testing.

The alignment of the rolls and the wedge is essential to achieve symmetrical displacement on the front and rear side of the sample.

\section{Results and Discussion}

This section is divided into three subsections. It provides a concise and precise description of the experimental results, their interpretations, and the conclusions that can be drawn.

\subsection{Experiments and Evaluation}

Tests with the newly developed device were carried out successfully between room temperature and $1470{ }^{\circ} \mathrm{C}$. During the high-temperature experiments, the furnace chamber was purged with argon and a purging rate up to $70 \mathrm{~L} / \mathrm{h}$. Figure 6 shows the load-displacement diagrams from room temperature to $1470{ }^{\circ} \mathrm{C}$.

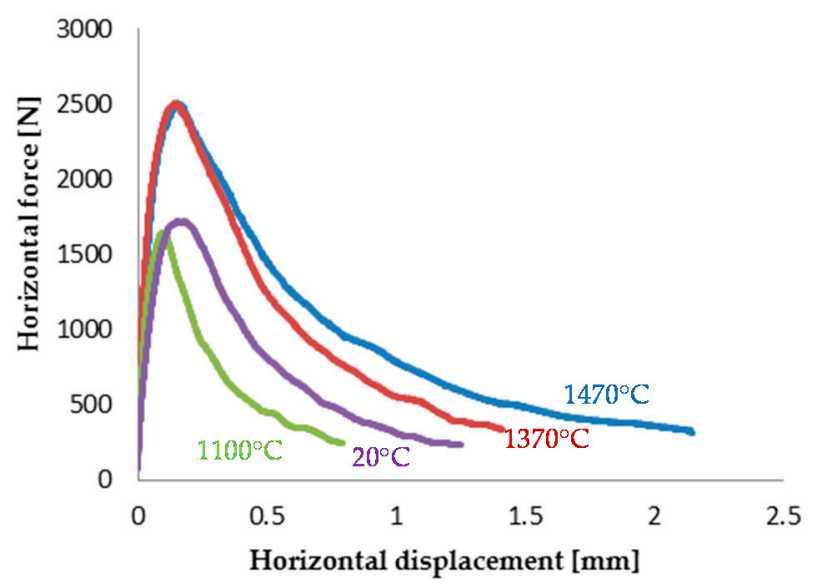

Figure 6. Load/displacement diagram of the magnesia carbon material measured at different temperatures.

As the oxidation of carbon in the sample increases with increasing temperature, a purging rate was defined for each individual temperature. The purging rate at $1100^{\circ} \mathrm{C}$ was set to $10 \mathrm{~L} / \mathrm{h}$, at $1370{ }^{\circ} \mathrm{C}$ $40 \mathrm{~L} / \mathrm{h}$ and to $70 \mathrm{~L} / \mathrm{h}$ for the test at $1470{ }^{\circ} \mathrm{C}$.

The Table 1 below shows the maximum horizontal force $F_{H, \max }$, the specific fracture energy $G f^{\prime}$ and the nominal notch tensile strength $\sigma_{N T}$ according to the Equations (1)-(3). 
Table 1. Fracture mechanical parameters determined from tests performed at room temperature (RT), $1100{ }^{\circ} \mathrm{C}, 1370{ }^{\circ} \mathrm{C}$, and $1470{ }^{\circ} \mathrm{C}$.

\begin{tabular}{ccccc}
\hline & $\mathbf{2 0}^{\circ} \mathbf{C}(\mathbf{R T})$ & $\mathbf{1 1 0 0}{ }^{\circ} \mathbf{C}$ & $\mathbf{1 3 7 0}^{\circ} \mathbf{C}$ & $\mathbf{1 4 7 0}^{\circ} \mathbf{C}$ \\
\hline$F_{V \max }[\mathrm{N}]$ & 301 & 288 & 439 & 440 \\
$F_{H \max }[\mathrm{N}]$ & 1720 & 1646 & 2508 & 2510 \\
Specific fracture energy $G_{f}{ }^{\prime}[\mathrm{N} / \mathrm{m}]$ & 240 & 125 & 362 & 513 \\
Nominal notch tensile strength $\sigma_{N T}\left[\mathrm{~N} / \mathrm{mm}^{2}\right]$ & 2.71 & 3.13 & 4.02 & 4.35 \\
$G_{f} / \sigma_{N T}[\mathrm{~mm}]$ & 0.09 & 0.04 & 0.09 & 0.12 \\
\hline
\end{tabular}

For the high-temperature tests the specific fracture energy $G_{f}{ }^{\prime}$ and the nominal notch tensile strength $\sigma_{N T}$ show an increase with increasing temperature. The test at room temperature shows the smallest nominal notch tensile strength but the specific fracture energy $G_{f}$ 'is higher than that at 1100 ${ }^{\circ} \mathrm{C}$ and lower than that at $1370{ }^{\circ} \mathrm{C}$. The ratio between the specific fracture energy $G_{f}$ ' and the notch tensile strength $\sigma_{N T}$ are applied as an indicator for brittleness [8].

The following figure illustrates a sample after the experiment at $1470{ }^{\circ} \mathrm{C}$. The oxidation of the carbon in the sample is relatively small, only slight traces of oxidation are visible on the surface. The ligament area of the sample (the area inside the red frame) is without any visible oxidation (Figure 7).

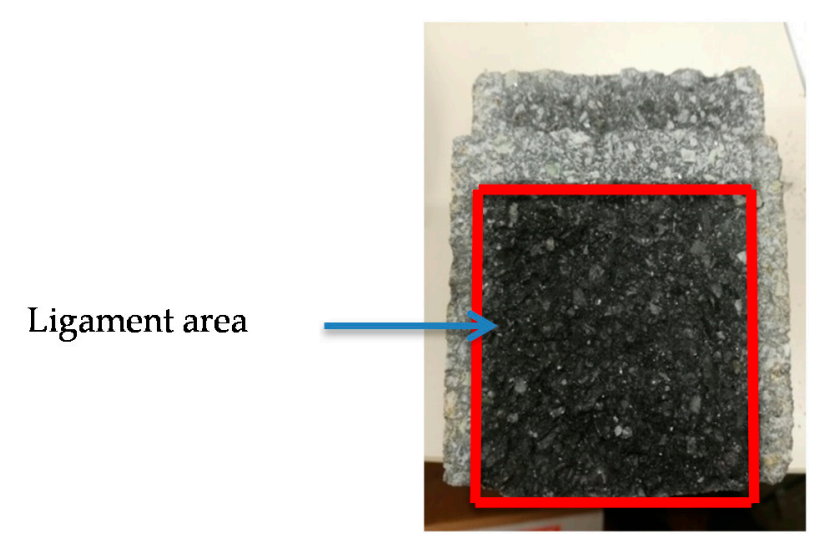

Figure 7. Sample after a wedge-splitting test at $1470{ }^{\circ} \mathrm{C}$.

The weight loss after the test at $1470{ }^{\circ} \mathrm{C}$ is below $1 \%$ (18 g out of $2250 \mathrm{~g}$ of a sample in virgin state) for a purging rate of $70 \mathrm{~L} / \mathrm{h}$. The reaction of $\mathrm{C}(\mathrm{s})$ with $\mathrm{O}_{2}(\mathrm{~g})$ decreases with an increase in the argon purging rate [9]. The weight loss after the test at $1370{ }^{\circ} \mathrm{C}$ is $0.8 \%$. For the test at $1100{ }^{\circ} \mathrm{C}$, the weight loss decreases to $0.5 \%$.

\subsection{Inverse Evaluation}

In order to determine other parameters of interest, such as the tensile strength $f_{t}$ and the total specific fracture energy $G_{f}$ and to consider the influence of the creep behavior, an inverse evaluation method was applied on a two-dimensional finite element model of the wedge splitting test developed earlier [10]. The commercial software package ABAQUS (6.13, Dassault Sys Simulia Corp, Providence, RI, USA) was used for modeling. The mode I fracture was considered with an exponential strain-softening behavior applied in the ligament area (Figure 8) (Equation (4)).

$$
\sigma=f_{t}\left\{1-\left(\frac{1-e^{-\varphi \frac{x}{x_{u l t}}}}{1-e^{-\varphi}}\right)\right\}
$$




\section{Ligament area}

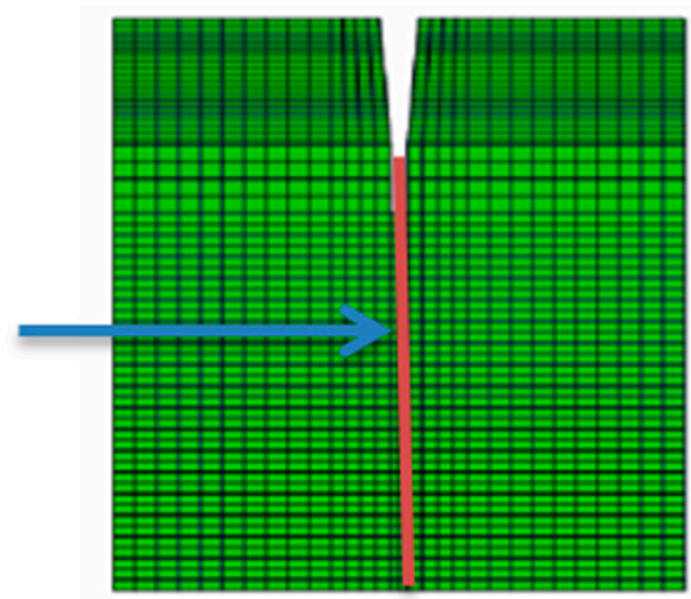

Figure 8. Finite element model geometry and mesh.

In this equation $f_{\mathrm{t}}$ is the tensile strength of the material, the parameter $x_{u l t}$ is the ultimate crack opening and $\varphi$ is a non-dimensional parameter that defines the rate of damage evolution [11]. Cohesive elements were applied to the interfaces of the two half specimens to simulate the mode I fracture [11]. Through an adaptive nonlinear least-squares algorithm, the fracture parameters are inversely calculated by fitting the results of finite element simulations to the results of laboratory wedge splitting tests.

The following Figures 9-11 show the load-displacement diagrams and the determined strain-softening behavior for experiments between $1100{ }^{\circ} \mathrm{C}$ and $1470{ }^{\circ} \mathrm{C}$. The green curves in the left diagrams (a) are the measured ones from the wedge splitting tests. The blue curves (a) are the curves simulated by finite element simulations. The red curves in the diagrams show the results with consideration of the creep behavior and are explained in the following chapter. The (b) figures show the strain-softening behavior determined via inverse evaluation from parameters $f_{\mathrm{t}}, x_{u l t}$, and $\varphi$. Results from (b) correspond to (a).
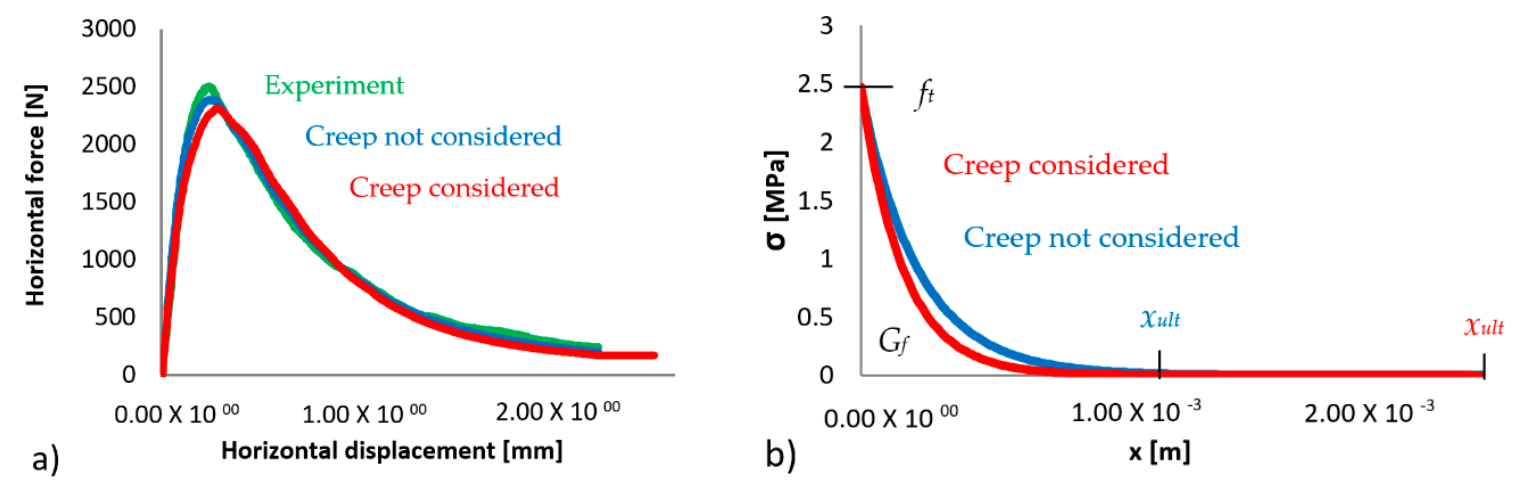

Figure 9. Load-displacement diagram (a) and strain-softening behavior (b) at $1470{ }^{\circ} \mathrm{C}$. 

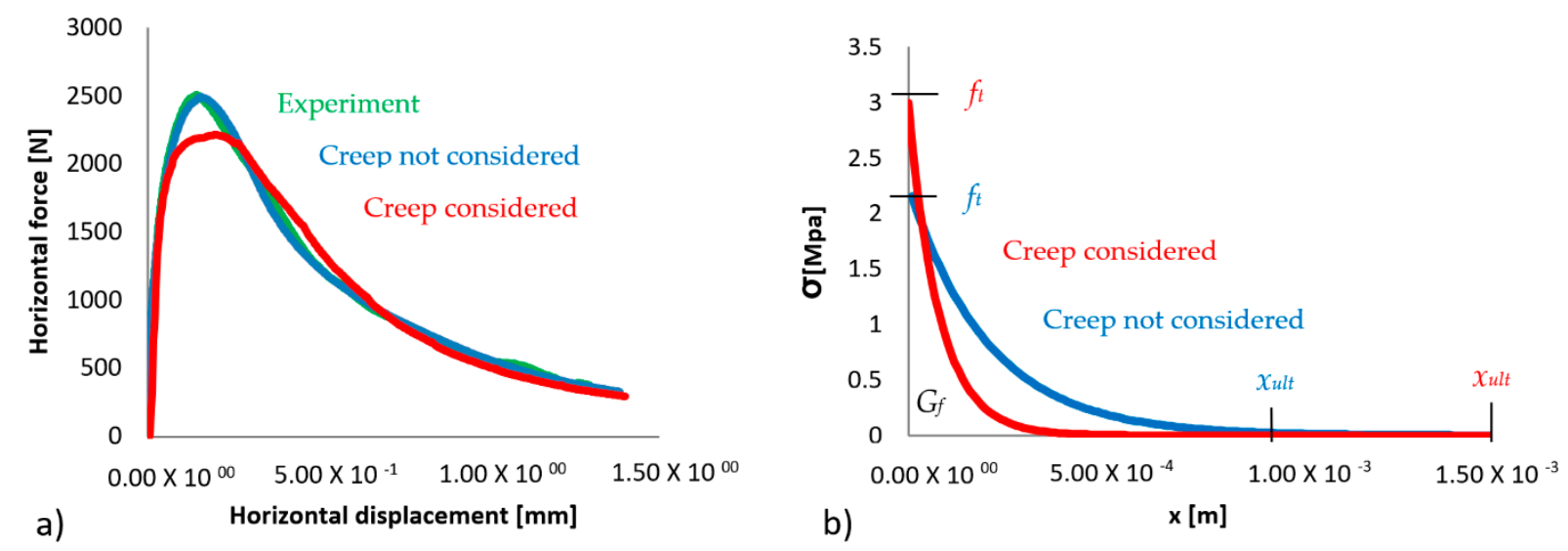

Figure 10. Load-displacement diagram (a) and strain-softening behavior (b) at $1370{ }^{\circ} \mathrm{C}$.
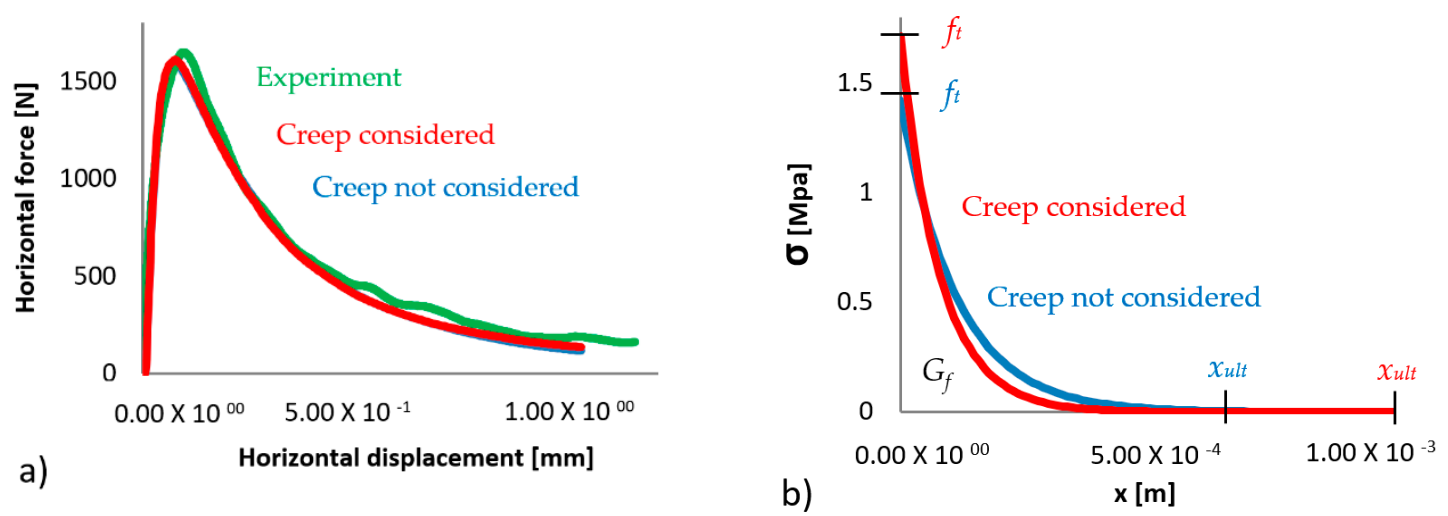

Figure 11. Load-displacement diagram (a) and strain-softening behavior (b) at $1100{ }^{\circ} \mathrm{C}$.

The inversely calculated curve (a) shows only a slight deviation from the tested one. The minimization procedure is automatically terminated when a minimum of residuals is reached [10]. The tensile strength and $x_{u l t}$ show a decrease with decreasing temperature when the creep is not considered.

Table 2 shows the inversely evaluated parameters and brittleness indicators.

Table 2. Fracture mechanical parameters and brittleness indicators at different temperatures calculated from ABAQUS simulations.

\begin{tabular}{cccc}
\hline Parameter & $\mathbf{1 4 7 0}{ }^{\circ} \mathbf{C}$ & $\mathbf{1 3 7 0}^{\circ} \mathbf{C}$ & $\mathbf{1 1 0 0}{ }^{\circ} \mathbf{C}$ \\
\hline Total specific fracture energy $G_{f}[\mathrm{~N} / \mathrm{m}]$ & 563 & 453 & 162 \\
Tensile strength $f_{t}\left[\mathrm{~N} / \mathrm{mm}^{2}\right]$ & 2.40 & 2.26 & 1.42 \\
$\sigma_{N T} / f_{t}$ & 1.83 & 1.77 & 2.2 \\
$G_{f} / f_{t}[\mathrm{~mm}]$ & 0.23 & 0.20 & 0.11 \\
\hline
\end{tabular}

With increasing temperature, the specific fracture energy $G_{f}$ increases. The tensile strength follows the same trend. At $1470{ }^{\circ} \mathrm{C}$ and $1370{ }^{\circ} \mathrm{C}$, the maximum horizontal forces are similar but the specific fracture energy is lower at $1370{ }^{\circ} \mathrm{C}$ because of lower horizontal displacement.

Additionally, the ratio between $\sigma_{N T}$ and $f_{\mathrm{t}}$ was calculated. The difference between $\sigma_{N T}$ and $f_{\mathrm{t}}$ is expected. Reasons are the action of the notch on the one hand and on the other hand the dependence on the brittleness number [12]. As well as $G_{f}^{\prime} / \sigma_{N T}$, the ratio between the real specific fracture energy $G_{f}$ and the tensile strength $f_{\mathrm{t}}$ is an indicator of the brittleness. This ratio decreases with decreasing temperature. 


\subsection{Inverse Evaluation with the Consideration of Creep}

In this chapter, the tensile creep behavior was considered in the inverse evaluation. The creep behavior of this material was already investigated by the authors [13]. It is clear that creep has an influence on the service behavior and furthermore on the results of the high-temperature wedge splitting test. The aim of these simulations is to calculate the specific fracture energy, which is caused by crack propagation only. The contribution of creep depends on the loading rate. For low loading rates, the influence of creep is comparatively high and vice versa for high loading rates. The Norton-Bailey creep equation was applied (Equation (5)).

$$
\dot{\varepsilon}_{c r}=K(T) \sigma^{n} \varepsilon_{c r}^{a}
$$

Here, $\sigma$ is the applied load, $\dot{\varepsilon}_{c r}$ is the creep strain rate, $\varepsilon_{c r}$ is the creep strain, $K(T)$ is a temperature-dependent function and the parameters $n$ and $a$ are the stress and strain exponents, respectively.

These parameters were implemented in the simulation of the wedge-splitting test and the creep behavior was considered in the whole specimen volume. The diagrams (Figures 9-11) in Section 4.2 shows the results in detail. The left diagrams (a) at each temperature show the experimental curve and the fits, both, with and without consideration of creep. The strain-softening behavior, which is plotted on the right side in Figures $9 b, 10 b$ and $11 b$, shows the change of the energy and the tensile strength of the material at each temperature.

Table 3 shows the change of the parameter with respect to temperature when creep is considered. The inverse calculated parameter $G_{f}$ shows an increase of the specific fracture energy with increasing temperature. The ratio between the specific fracture energy and the tensile strength that is related to the brittleness shows, for both cases (with and without consideration of creep), an increase with increasing temperature. The difference between $G_{f}$ with consideration of creep and $G_{f}$ without consideration of creep (Table 2), $\Delta G_{f}$, shows a maximum temperature of $1370{ }^{\circ} \mathrm{C}$ and is between $15 \%$ and $47 \%$ for the high-temperature tests.

Table 3. Fracture mechanical parameters at different temperatures calculated considering creep and influence on $G_{f}$.

\begin{tabular}{cccc}
\hline Parameter & $\mathbf{1 4 7 0}{ }^{\circ} \mathbf{C}$ & $\mathbf{1 3 7 0}{ }^{\circ} \mathbf{C}$ & $\mathbf{1 1 0 0}{ }^{\circ} \mathbf{C}$ \\
\hline Specific fracture energy $G_{f}$, creep considered $[\mathrm{N} / \mathrm{m}]$ & 417 & 238 & 137 \\
$\Delta G_{f}[\mathrm{~N} / \mathrm{m}]$ & $146(26 \%)$ & $215(47 \%)$ & $25(15 \%)$ \\
Tensile strength $f_{t}$, creep considered $\left[\mathrm{N} / \mathrm{mm}^{2}\right]$ & 2.47 & 2.99 & 1.71 \\
$G_{f} / f_{t}$, creep considered $[\mathrm{mm}]$ & 0.17 & 0.08 & 0.08 \\
\hline
\end{tabular}

\section{Conclusions}

A new testing device to perform the WST was introduced in this paper. This new device allows fracture mechanical characterization of carbon-containing refractories up to $1500{ }^{\circ} \mathrm{C}$ under reducing conditions. Tests on resin bonded magnesia carbon material were successfully carried out. The oxidation of the carbon in the sample during the high-temperature test can be avoided by inert gas purging during the whole test. The displacement measurement directly on the sample shows a resolution below $3 \mu \mathrm{m}$ and works stably over the whole temperature range. Based on the data obtained from laboratory experiments, fracture parameters can be determined and implemented in finite element simulations with an inverse estimation procedure. Besides, simulations including the tensile creep behavior were performed and the fracture parameters under pure mode I failure were determined. The influence of creep on the results obtained from the inverse evaluation for the specific fracture energy is between $15 \%\left(1100{ }^{\circ} \mathrm{C}\right)$ and $47 \%\left(1370{ }^{\circ} \mathrm{C}\right)$. 
Author Contributions: Conceptualization, M.S. and D.G.; Methodology, M.S.; Software, S.J.; Validation, D.G., S.J. and H.H.; Formal Analysis, M.S. and. S.J.; Investigation, M.St.; Resources, M.S. and D.G.; Data Curation, D.G.; Writing—Original Draft Preparation, M.S.; Writing—Review \& Editing, D.G.; Visualization, M.S.; Supervision, H.H.; Project Administration, D.G.; Funding Acquisition, H.H.

Acknowledgments: This research was funded by K1-MET GmbH, metallurgical competence center. The research program of the competence center K1-MET is supported by COMET (Competence Centre for Excellent Technologies), the Austrian program for competence centers. COMET is funded by the Federal Ministry for Transport, Innovation and Technology, the Federal Ministry for Science, Research and Economy, the province of Upper Austria, Tyrol, and Styria, the Styrian Business Promotion Agency. The authors gratefully thank the company ZwickRoell Testing Systems $\mathrm{GmbH}$ (former Messphysik Materials Testing $\mathrm{GmbH}$ ) for the good cooperation and manufacturing of the newly developed device.

Conflicts of Interest: The authors declare no conflict of interest

\section{References}

1. Harmuth, H.; Rieder, K.; Krobath, M.; Tschegg, E. Investigation of the nonlinear fracture behaviour of ordinary ceramic refractory materials. Mater. Sci. Eng. A Struct. 1996, 214, 53-61. [CrossRef]

2. Tschegg, E. Equipment and Appropriate Specimen Shapes for Tests To Measure Fracture Values. Austria Patent 390328, 31 January 1986.

3. Brochen, E.; Dannert, C. Thermo-mechanical characterisation of magnesia-carbon refractories by means of wedge splitting test under controlled atmosphere at high-temperature. In Proceedings of the 13th Biennial Worldwide Congress UNITECR 2013, Victoria, BC, Canada, 10-13 September 2013.

4. Dai, J.; Gruber, D.; Harmuth, H. Determination of the fracture behaviour of MgO-refractories using multi-cycle wedge splitting test and digital image correlation. J. Eur. Ceram. Soc. 2017, 37, 5035-5043. [CrossRef]

5. Zhu, T.; Li, Y.; Luo, M.; Sang, S.; Wang, Q.; Zhao, L.; Li, Y.; Li, S. Microstructure and mechanical properties of $\mathrm{MgO}-\mathrm{C}$ refractories containing graphite oxide nanosheets (GONs). Ceram. Int. 2013, 39, 3017-3025. [CrossRef]

6. Mahato, S.; Shantanu, K.; Behera, K. Oxidation resistance and microstructural evolution in MgO-C refractories with expanded graphite. Ceram. Int. 2016, 42, 7611-7619. [CrossRef]

7. Song, J.; Yang, J.; Liu, F.; Lu, K. High temperature strain measurement method by combining digital image correlation of laser speckle and improved RANSAC smoothing algorithm. Opt. Lasers Eng. 2018, 111, 8-18. [CrossRef]

8. Harmuth, H.; Bradt, R.C. Investigation of refractory brittleness by fracture mechanical and fractographic methods. InterCeram Int. Ceram. Rev. 2010, 62, 6-10.

9. Faghihi-Sani, M.; Yamaguchi, A. Oxidation kinetics of MgO-C refractory bricks. Ceram. Int. 2002, 28, 835-839. [CrossRef]

10. Jin, S.; Gruber, D.; Harmuth, H. Determination of Young's modulus, fracture energy and tensile strength of refractories by inverse estimation of a wedge splitting procedure. Eng. Fract. Mech. 2014, 116, 228-236. [CrossRef]

11. Abaqus 6.13 Documentation. Available online: http://dsk.ippt.pan.pl/docs/abaqus/v6.13/index.html (accessed on 4 July 2019).

12. Auer, T.; Harmuth, H. Numerical simulation of a fracture test for brittle disordered materials. In Proceedings of the 16th European Conference of Fracture, Alexandroupolis, Greece, 3-7 July 2006.

13. Stueckelschweiger, M.; Gruber, D.; Jin, S.; Harmuth, H. Creep testing of carbon containing refractories under reducing conditions. Ceram. Int. 2019, 45, 9776-9781. [CrossRef]

(C) 2019 by the authors. Licensee MDPI, Basel, Switzerland. This article is an open access article distributed under the terms and conditions of the Creative Commons Attribution (CC BY) license (http://creativecommons.org/licenses/by/4.0/). 